\title{
Feasibility of a modified search, coagulation, and clipping method with and without the use of polyglycolic acid sheets and fibrin glue for preventing delayed bleeding after gastric endoscopic submucosal dissection
}

\author{
Satoshi Abiko ${ }^{1,2^{*}} \mathbb{0}$, Soichiro Oda ${ }^{1}$, Akimitsu Meno ${ }^{1}$, Akane Shido ${ }^{1}$, Sonoe Yoshida ${ }^{1}$, Ayumu Yoshikawa ${ }^{1}$,
} Kazuaki Harada' ${ }^{1}$ Naoki Kawagishi', Itsuki Sano ${ }^{1}$, Hisashi Oda ${ }^{1}$ and Takuto Miyagishima ${ }^{1}$

\begin{abstract}
Background: Methods have been developed for preventing delayed bleeding (DB) after gastric endoscopic submucosal dissection (GESD). However, none of the methods can completely prevent DB. We hypothesized that DB could be prevented by a modified search, coagulation, and clipping (MSCC) method for patients at low risk for DB and by combining the use of polyglycolic acid sheets and fibrin glue with the MSCC method (PMSCC method) for patients at high risk for DB (antibleeding [ABI] strategy). This study assessed the technical feasibility of this novel strategy.

Method: We investigated 123 lesions in 121 consecutive patients who underwent GESD in Kushiro Rosai Hospital between April 2018 and January 2020. The decision for continuation or cessation of antithrombotic agents was based on the Guidelines for Gastroenterological Endoscopy in Patients Undergoing Antithrombotic Treatment.

Results: Oral antithrombotic agents were administered to 28 patients (22.8\%). The en bloc R0 resection rate was 98.4\%. The MSCC method and the PMSCC method for preventing DB were performed in 114 and 9 lesions, respectively. The median time of the MSCC method was $16 \mathrm{~min}$, and the median speed (the resection area divided by the time of method used) was $3.6 \mathrm{~cm}^{2} / 10 \mathrm{~min}$. The median time of the PMSCC method was $59 \mathrm{~min}$, and the median speed was $1.3 \mathrm{~cm}^{2} / 10 \mathrm{~min}$. The only delayed procedural adverse event was DB in $1(0.8 \%)$ of the 123 lesions.
\end{abstract}

Conclusions: The ABI strategy is feasible for preventing DB both in patients at low risk and in those at high risk for DB after GESD, whereas the PMSCC method may be necessary for reduction of time.

Keywords: Delayed bleeding, Gastric endoscopic submucosal dissection, Polyglycolic acid sheets

\section{Background}

Gastric cancer is the fifth most common cancer worldwide, and endoscopists in Eastern Asian countries detect $50-70 \%$ of gastric cancers at an early stage [1-4].

*Correspondence: abiko1982@gmail.com

1 Department of Gastroenterology, Kushiro Rosai Hospital, Kushiro, Japan

Full list of author information is available at the end of the article
Gastric endoscopic submucosal dissection (GESD) is a widespread technique for treatment of gastric epithelial neoplasms $[4,5]$. However, post-ESD bleeding is a serious complication after GESD, with a reported incidence of 3-5.5\% [6-11]. This complication sometimes results in shock requiring transfusion. A safe, simple, and costefficient method of preventing post-ESD bleeding should be developed. Post-ESD coagulation (PEC) has been used 
in many hospitals to prevent post-ESD bleeding [6]. The search, coagulation, and clipping (SCC) method has been reported to be much better than the PEC method for preventing post-ESD bleeding [12]. However, the SCC method does not completely prevent post-ESD bleeding. Another approach combines the use of polyglycolic acid (PGA) sheets and fibrin glue to reduce the risk of DB after GESD [13]. However, a multicenter, prospective, randomized controlled study showed that PGA sheets alone were not effective in preventing $\mathrm{DB}$ in patients at high risk for such bleeding [14]. We have devised a new method of preventing DB after GESD by combining the use of PGA sheets and fibrin glue with a modified SCC method [15]. We hypothesized that DB could be prevented by a modified SCC method (MSCC method) for patients at low risk for DB and by combining the use of PGA sheets and fibrin glue with the MSCC method (PMSCC method) for patients at high risk for DB (antibleeding $[\mathrm{ABI}]$ strategy). This study assessed the technical feasibility of this novel strategy.

\section{Methods \\ Study design}

This study was a retrospective case series.

\section{Subjects}

We investigated 123 lesions in 121 consecutive patients who underwent GESD in the Department of Gastroenterology at Kushiro Rosai Hospital between April 2018 and January 2020. The surgeries were performed by an endoscopist (S.A.) and trainees with experience of fewer than 30 ESD procedures in humans. All of the procedures were tutored by one endoscopist (S.A.). Until March 2018, ESD was performed in 169 patients (pharynx in 1 patient, esophagus in 16 patients, stomach in 128 patients, and large intestine in 24 patients) under the guidance of tutors at other institutions. Perforation and delayed perforation did not occur in any cases, and DB occurred in four cases (3.1\%, ESD of the stomach). From April 2018, S.A. was the only endoscopist for ESD at our institution. Patients at high risk for DB were classified as patients being administered direct oral anticoagulants (DOACs) or warfarin, patients on dialysis, and patients who had received heparin replacement. Other patients were classified as patients at low risk for DB. We evaluated the number of en bloc R0 resections; the number of curative resections; length of the tumor; length of the resected specimen; resection area; resection time; resection speed; method of preventing DB; number of clips used for the MSCC method; time and speed of the PEC, MSCC, and PMSCC methods with and without the use of second-look endoscopy and vonoprazan; the number of procedures at the second-look or follow-up endoscopy; and procedural and delayed procedural adverse events, including perforation during ESD, delayed perforation, DB, and post-ESD stenosis. En bloc $\mathrm{R} 0$ resection was defined as resection of the tumor in a single piece with tumor-free lateral and vertical margins. Resection time was the duration from the first injection until achievement of complete resection. Resection speed was defined as the resection area divided by the resection time $\left(\mathrm{cm}^{2} / \mathrm{h}\right)$. The resection area was regarded as being approximately oval in shape. The time of the PEC, MSCC, and PMSCC methods was defined as the interval from insertion of the first device for the prevention of $\mathrm{DB}$ until completion of the method. The speed of the PEC, MSCC, and PMSCC methods was defined as the resection area divided by $10 \times$ the time of the PEC, MSCC, and PMSCC methods $\left(\mathrm{cm}^{2} / 10 \mathrm{~min}\right)$. Perforation was defined as the creation of an immediately recognized hole in the gastric wall. Delayed perforation was defined as the presence of free air on abdominal computed tomography or $\mathrm{X}$-ray after completion of the procedure in patients without perforation during ESD and no symptoms of peritoneal irritation after ESD. DB was defined as bleeding requiring emergency endoscopic hemostasis or transfusion or the presence of hemoglobin loss $\geq 2 \mathrm{~g} / \mathrm{dL}$ following ESD [16]. Delayed procedural adverse events were assessed for 30 days post-ESD. Continuation or cessation of antithrombotic agents was determined according to the Guidelines for Gastroenterological Endoscopy in Patients Undergoing Antithrombotic Treatment [17, 18]. We examined $A B O$ blood type because it has been reported that blood type $\mathrm{O}$ may be less likely to clot than other types [19].

\section{ESD method and management after ESD}

GIF-H290Z (Olympus Optical, Tokyo, Japan) and a needle knife were used for assessing the lesion margin and marking around the lesion. ESD was performed with the patient under conscious sedation using a single-channel gastrointestinal endoscope with a transparent attachment hood fitted to the tip (GIF-Q260J; Olympus Optical). When difficulties were observed, we used another twinchannel gastrointestinal endoscope (GIF-2TQ260M; Olympus Optical). The GIF-2TQ260M endoscope has a multi-bending and a water jet function. Hyaluronic acid solution was injected into the submucosal layer before mucosal and submucosal cutting. After injection, we mainly performed mucosal cutting with a needle knife and dissection beneath the lesion using an IT knife-2 (Olympus Optical). When difficulties were observed, we used a hook knife (Olympus Optical), flush knife (Fujifilm Optical), or clutch cutter (Fujifilm Optical). We used a VIO 200D electrosurgical generator (ERBE Elektromedizin, Tübingen, Germany). Hemorrhage was controlled 
using hemostatic forceps such as Coagrasper (Olympus Optical monopolar hot hemostasis forceps) for the upper digestive tract.

After ESD, a proton-pump inhibitor (omeprazole $20 \mathrm{mg}$ twice a day) was intravenously injected. The patient's doctor in the ward rarely ordered a second-look endoscopy to be performed on postoperative day (POD) 1 . If there were no problems, oral food intake was started on POD 2. Then an oral proton-pump inhibitor (esomeprazole $20 \mathrm{mg} /$ day, lansoprazole $30 \mathrm{mg} /$ day, or rabeprazole $20 \mathrm{mg} /$ day) or vonoprazan $(20 \mathrm{mg} /$ day $)$ was administered for a minimum of 8 weeks. Sodium alginate $(60 \mathrm{~mL} /$ day) and aluminum hydroxide gel, magnesium hydroxide $(160 \mathrm{~mL} /$ day $)$ were administered for a minimum of 3 days. Before the patient was discharged from the hospital, follow-up endoscopy was performed on POD 5-7.

\section{Methods for prevention of DB}

We previously described a new method combining the use of PGA sheets and fibrin glue with a modified SCC method for preventing DB after GESD [15]. First, a coagulation procedure was performed after resection of the lesion, mainly in the vessels at the margin of the ulcer base. Then, the perforator vessels emerging between the muscle layers were actively sought and clipped using short hemoclips (HX-610-135S, Olympus Optical). Because perforator vessels may also be present in the carbonized areas of the ulcer base, clipping was also actively performed in such areas; this constituted the modification of the SCC method. For patients at low risk for DB, we ended with this procedure. For patients at high risk for DB, we moved on to the next procedure. In the next procedure, several large and small PGA sheets were placed (based on the size of the ulcer base), using methods described by Kobayashi et al. [20] and Takimoto et al. [21]. Finally, fibrin glue was sprayed. All these steps constituted the polyglycolic acid sheets, fibrin glue, and modified search, coagulation, and clipping (PMSCC) method.

\section{Pathological assessment of resected specimens}

The resected specimens from the stomach were cut into longitudinal slices 2 to $3 \mathrm{~mm}$ in width that were embedded in paraffin. The slices were stained with hematoxylin-eosin and examined microscopically. Curative resection of adenocarcinoma was previously described by the Japanese Gastric Cancer Association [22].

\section{Ethical approval}

The study was conducted in accordance with the rules and regulations of the Kushiro Rosai Hospital Institutional Review Board (study registration number: 19233) and conformed to the requirements of the Declaration of
Helsinki. Written informed consent was obtained from all study subjects.

\section{Statistical analysis}

All statistical analyses were performed with EZR (Saitama Medical Center, Jichi Medical University, Saitama, Japan), which is a graphical user interface for R (The R Foundation for Statistical Computing, Vienna, Austria). More precisely, EZR is a modified version of $\mathrm{R}$ commander designed to add statistical functions frequently used in biostatistics [23]. Continuous and nonparametric variables were expressed as medians with 25 th and 75 th percentile values. The Mann-Whitney $U$ test was used for comparisons of continuous and nonparametric variables, and the Fisher exact test was used for comparisons of categorical variables. Differences were considered statistically significant at a $P$ value $<0.05$.

\section{Results}

The median age of the subjects was 73 (interquartile range [IQR], 69-79) years, and the male/female ratio was $98 / 25$. Oral antithrombotic agents were administered to 28 patients $(22.8 \%)$. The lesion sites were upper $(n=16)$, middle $(n=59)$, and lower $(n=48)$ portions of the stomach. The median length of the long tumor axis was 1.3 (IQR $0.7-2.0) \mathrm{cm}$, the median resected specimen length was 3.0 (IQR 2.5-4.1) cm, and the median resection area was 5.5 (IQR 3.5-9.4) $\mathrm{cm}^{2}$ (Table 1). The en bloc R0 resection rate was $98.4 \%$, and the curative resection rate was $87.0 \%$. The median resection time was 91 (IQR 55-137) $\mathrm{min}$ and the median resection speed was 4.5 (IQR 2.5-5.4) $\mathrm{cm}^{2} / \mathrm{h}$. The MSCC and PMSCC methods for preventing DB were performed in 114 and 9 lesions, respectively. The median time of the MSCC method was 16 (IQR 8-23) min, and the median speed was 3.6 (IQR 2.8-4.1) $\mathrm{cm}^{2} / 10 \mathrm{~min}$. The median time of the PMSCC method was 59 (IQR 44-63), min and the median speed was 1.3 (IQR $1.2-2.4$ ) $\mathrm{cm}^{2} / 10 \mathrm{~min}$. The only delayed procedural adverse event was DB in $1(0.8 \%)$ of the 123 lesions. There were no significant differences in the results and clinical course of GESD between patients treated with MSCC and those treated with PMSCC (Table 2).

Table 3 shows details of the nine patients in whom the PMSCC method was used. The PMSCC method was used in nine patients at high risk for DB for the following reasons: heparin replacement (one patient), hemodialysis (two patients), direct oral anticoagulant administration (three patients), and oral warfarin administration (three patients). DB did not occur in any of the nine patients (Table 3). 
Table 1 Characteristics of patients and lesions

\begin{tabular}{|c|c|}
\hline Characteristic & Value \\
\hline \multicolumn{2}{|l|}{ Age } \\
\hline Median (IQR), years & $73(69-79)$ \\
\hline \multicolumn{2}{|l|}{ Sex } \\
\hline Male/female & $98 / 25$ \\
\hline \multicolumn{2}{|c|}{ Oral antithrombotic agents, $n(\%)$} \\
\hline None & $95(77.2)$ \\
\hline Warfarin & $3(2.4)$ \\
\hline DOAC & $3(2.4)$ \\
\hline DAPT & $1(0.8)$ \\
\hline Clopidogrel & $3(2.4)$ \\
\hline Aspirin & $7(5.7)$ \\
\hline Aspirin + others & $1(0.8)$ \\
\hline Cilostazol & $2(1.6)$ \\
\hline Others & $8(6.5)$ \\
\hline Dialysis, $n$ (\%) & $2(1.6)$ \\
\hline Heparin replacement, $n(\%)$ & $1(0.8)$ \\
\hline \multicolumn{2}{|l|}{ Lesion site, $n(\%)$} \\
\hline Upper & $16(13.0)$ \\
\hline Middle & $59(48.0)$ \\
\hline Lower & $48(39.0)$ \\
\hline \multicolumn{2}{|l|}{ Length of resected specimen } \\
\hline Median (IQR), cm & $3.0(2.5-4.1)$ \\
\hline \multicolumn{2}{|l|}{ Resection area } \\
\hline Median (IQR), $\mathrm{cm}^{2}$ & $5.5(3.5-9.4)$ \\
\hline \multicolumn{2}{|l|}{ Length of tumor } \\
\hline Median (IQR), cm & $1.3(0.7-2.0)$ \\
\hline \multicolumn{2}{|l|}{ Pathological diagnosis, $n$ (\%) } \\
\hline Adenocarcinoma & $106(86.2)$ \\
\hline Adenoma & $14(11.4)$ \\
\hline Others & $3(2.4)$ \\
\hline \multicolumn{2}{|l|}{ Depth, $n(\%)$} \\
\hline Intramucosa & $99(80.5)$ \\
\hline Submucosa & $24(19.5)$ \\
\hline \multicolumn{2}{|l|}{ Macroscopic type, $n$ (\%) } \\
\hline Depressed & $52(42.3)$ \\
\hline Nondepressed & $71(57.7)$ \\
\hline \multicolumn{2}{|l|}{ Submucosal fibrosis, $n$ (\%) } \\
\hline Negative & $107(87.0)$ \\
\hline Positive & $16(13.0)$ \\
\hline \multicolumn{2}{|l|}{ Blood type, $n(\%)$} \\
\hline O & $40(32.5)$ \\
\hline A & $37(30.1)$ \\
\hline B & $35(28.5)$ \\
\hline$A B$ & $11(8.9)$ \\
\hline
\end{tabular}

DAPT dual antiplatelet therapy, DOAC direct oral anticoagulant, IQR interquartile range, $P M S C C$ polyglycolic acid sheets and fibrin glue combined with the modified search, coagulation, and clipping method

\section{Discussion}

In this study, we investigated the technical feasibility of this novel strategy and found that DB occurred in only one patient, the time of the MSCC method was acceptable, the use of the PMSCC method prevented DB in patients at high risk for DB after GESD, and the time of the PMSCC method was not acceptable.

DB after ESD is a serious complication and should be prevented [7]. The incidence of DB after GESD has been reported to be $3-5.5 \%$ [6-11], and the incidence of DB in patients receiving antithrombotic therapy after ESD has been reported to be 21-38\% [24-27]. Methods for the prevention of DB after ESD were reported by Takizawa et al. (the incidence of DB in all patients was 3.1\%) [6], Mukai et al. (the incidence of DB in all patients was 1.3\%) [28], Azumi et al. (the incidence of DB in all patients was 2.6\%) [12], and Kawata et al. (the incidence of DB in patients receiving continued antithrombotic therapy was 5.8\%) [13], but no methods completely prevent DB after ESD. We hypothesized that DB could be prevented by combining the use of PGA sheets and fibrin glue with the MSCC method (the PMSCC method) in patients at high risk for DB [15] compared with other studies. In this study, the incidence of $\mathrm{DB}$ in all patients was $0.8 \%$, and the incidence of $\mathrm{DB}$ in patients receiving antithrombotic therapy was $3.6 \%$. Thus, the ABI strategy may be useful for preventing DB in patients after GESD.

In recent years, attempts have been made to endoscopically suture the ulcer base for prevention of DB in patients after GESD. However, the stomach has a thick wall, and it is difficult for the sutures to be retained. It appears that the sutures can only be retained for a few days [29]. A recent study reported that the retention of the sutures was gradually improved, but the incidence of DB was 10\% [30]. With current endoscopic techniques, complete suture of the ulcer base in the stomach appears to be difficult. Therefore, the ABI strategy is a reasonable method for preventing DB in patients after GESD.

The region in which bleeding occurs in ESD is often carbonized. When a region becomes carbonized, it is difficult to recognize exposed blood vessels, and subsequent DB prevention measures may be neglected. With our method, clipping was actively performed at carbonized sites. If bleeding does not occur during ESD, exposed blood vessels can easily be recognized, which may be important for preventing DB.

With regard to the merits of the PMSCC method, although bleeding may be observed from perforator vessels in areas where the PGA sheets are peeled off [14], we believe that if perforator vessels at the base of ulcers are clipped in advance, such DB may be prevented. With regard to the limitations of the PMSCC method, it can be difficult to identify and clip all perforator vessels, and 
Table 2 Results and clinical course of gastric ESD

\begin{tabular}{|c|c|c|c|c|}
\hline Characteristic & Total $(n=123)$ & $\operatorname{MSCC}(n=114)$ & PMSCC $(n=9)$ & $P$ value \\
\hline En bloc R0 resection, $n(\%)$ & $121 / 123(98.4)$ & $112 / 114(98.2)$ & $9 / 9(100.0)$ & 1.0000 \\
\hline VM1, n (\%) & $2(1.6)$ & $2(1.8)$ & $0(0)$ & 1.0000 \\
\hline $\mathrm{HM} 1, n(\%)$ & $0(0)$ & $0(0)$ & $0(0)$ & \\
\hline Curative resection, $n(\%)$ & 107/123 (87.0) & $86 / 100(86.0)$ & $7 / 9(77.7)$ & 0.3312 \\
\hline Resection time (min), median (IQR) & $91(55-137)$ & $88(54-133)$ & $100(74-186)$ & 0.3486 \\
\hline Resection speed $\left(\mathrm{cm}^{2} / \mathrm{h}\right)$, median (IQR) & $4.5(2.6-6.2)$ & $4.5(2.6-6.2)$ & $4.0(2.2-5.2)$ & 0.7819 \\
\hline Surgeon, S.A. alone/others & $84 / 39$ & $77 / 37$ & $7 / 2$ & 0.7177 \\
\hline Time of PEC method (min), median (IQR) & $7(5-11)$ & $7(4-11)$ & $11(5-16)$ & 0.1060 \\
\hline Speed of PEC method ( $\left.\mathrm{cm}^{2} / 10 \mathrm{~min}\right)$, median (IQR) & $7.5(4.9-12.7)$ & $7.5(4.9-12.8)$ & $6.9(4.5-11.4)$ & 0.7449 \\
\hline Time of MSCC method (min), median (IQR) & $16(8-23)$ & $16(8-22)$ & $26(8-30)$ & 0.2574 \\
\hline Speed of MSCC method ( $\left.\mathrm{cm}^{2} / 10 \mathrm{~min}\right)$, median (IQR) & $4.0(2.7-7.1)$ & $4.0(2.7-6.9)$ & $4.3(2.8-7.7)$ & 0.6656 \\
\hline Number of clips used for MSCC method, $n$, median (IQR) & $4(1-7)$ & $4(1-7)$ & $4(4-8)$ & 0.3884 \\
\hline Time of PMSCC method ${ }^{a}$ (min), median (IQR) & & & $59(44-63)$ & \\
\hline Speed of PMSCC method ( $\left.\mathrm{cm}^{2} / 10 \mathrm{~min}\right)$, median (IQR) & & & $1.3(1.2-2.4)$ & \\
\hline Second-look endoscopy, n (\%) & $15(12.9)$ & $13(12.9)$ & $2(22.2)$ & 0.3015 \\
\hline Vonoprazan, $n(\%)$ & $99(80.5)$ & $90(78.9)$ & $9(100.0)$ & 0.2032 \\
\hline Perforation during ESD, $n(\%)$ & $0(0)$ & $0(0)$ & $0(0)$ & \\
\hline Delayed perforation, $n(\%)$ & $0(0)$ & $0(0)$ & $0(0)$ & \\
\hline Delayed bleeding, $n$ (\%) & $1(0.8)$ & $1(0.9)$ & $0(0)$ & 1.0000 \\
\hline Post-ESD stenosis, n (\%) & $0(0)$ & $0(0)$ & $0(0)$ & \\
\hline
\end{tabular}

ESD endoscopic submucosal dissection, HM1 horizontal margin positive, IQR interquartile range, MSCC modified search, coagulation, and clipping method, $P E C$ postESD coagulation, PMSCC polyglycolic acid sheets and fibrin glue combined with the modified search, coagulation, and clipping method, VM1 vertical margin positive

a Only the nine patients in whom PMSCC was performed are included

Table 3 Details of the nine patients in whom the PMSCC method was used

\begin{tabular}{|c|c|c|c|c|c|c|c|c|c|}
\hline Patient & Age (yr) & Sex & Lesion site & $\begin{array}{l}\text { Length } \\
\text { of resected } \\
\text { specimen }(\mathrm{cm})\end{array}$ & $\begin{array}{l}\text { Oral antithrombotic } \\
\text { agent }\end{array}$ & Dialysis & $\begin{array}{l}\text { Heparin } \\
\text { replacement }\end{array}$ & Vonoprazan & Blood type \\
\hline 1 & 78 & M & Lower & 4.3 & Aspirin & - & + & + & A \\
\hline 2 & 85 & M & Lower & 4.3 & Nicorandil & + & - & + & B \\
\hline 3 & 72 & M & Middle & 2.2 & Warfarin & - & - & + & A \\
\hline 4 & 74 & M & Middle & 4.8 & DOAC & - & - & + & A \\
\hline 5 & 66 & M & Upper & 4.1 & DOAC & - & - & + & A \\
\hline 6 & 66 & M & Middle & 7.0 & - & + & - & + & $\mathrm{O}$ \\
\hline 7 & 70 & M & Middle & 1.9 & Warfarin & - & - & + & $\mathrm{O}$ \\
\hline 8 & 74 & M & Middle & 4.0 & Warfarin & - & - & + & B \\
\hline 9 & 61 & M & Middle & 3.1 & DOAC + others & - & - & + & B \\
\hline
\end{tabular}

DOAC direct oral anticoagulant, PMSCC polyglycolic acid sheets and fibrin glue. Combined with the modified search, coagulation, and clipping method

depending on the meal, the PGA seat may be peeled off. It may be necessary for the patient to fast after application of the PMSCC method in patients at very high risk for DB after resuming antithrombotic agents.

DOACs are associated with gastrointestinal bleeding, and it has been hypothesized that nonabsorbed, active anticoagulant agents within the gastrointestinal tract induce bleeding of fragile mucosal defects [31]. In this study, fragile mucosal defects were protected by PGA sheets. Prevention of DOAC-related DB by the PMSCC method may be possible.

Hatta et al. derived and externally validated a prediction model for DB after GESD, with good performance metrics [32]. We were able to identify patients with a risk of DB after GESD but did not know how manage them. It is not practical to use the complicated PMSCC method in all 
patients. The simple MSCC method should be used in lowrisk patients, and the complicated PMSCC method should only be used in high-risk patients. In the future, we may decide which method to use depending on the number of DB risk factors.

The procedure time of the PMSCC method was not acceptable. However, we are now developing a new technique to shorten the procedure time of PMSCC. We hope to report the results soon.

The study had three main limitations. There was only one principal surgeon, the sample size was small, and the study design was retrospective. Future prospective studies with larger sample sizes and randomized controlled trials are needed to evaluate the utility of our method.

\section{Conclusions}

The ABI strategy is feasible for preventing DB in patients at low risk or at high risk for DB after GESD, whereas the PMSCC method may be necessary to reduce the time.

\begin{abstract}
Abbreviations
DB: Delayed bleeding; GESD: Gastric endoscopic submucosal dissection; MSCC: Modified the search, coagulation, and clipping; ABI: Anti-bleeding; PEC: Post-ESD coagulation; SCC: Search, coagulation, and clipping; ESD: Endoscopic submucosal dissection; PGA: Polyglycolic acid; POD: Postoperative day; IQR: Interquartile range; Gl: Gastrointestinal.
\end{abstract}

\section{Acknowledgements}

We express our deep gratitude to Dr. Syunichiro Nozawa, Dr. Kensuke Sakurai, Dr Rui Sasaki and Dr. Yoshimitsu Kobayashi in the Department of Gastroenterology, Kushiro Rosai Hospital for their kind support and advice. We are very grateful to the wonderful staff in the endoscopic room of Kushiro Rosai Hospital.

\section{Authors' contributions}

SA wrote the manuscript. SO, AM, AS, SY, AY, KH, NK, IS, HO and TM edited the manuscript. SA is the article guarantor. All authors read and approved the final manuscript.

\section{Funding}

None.

\section{Availability of data and materials}

From the corresponding author on reasonable request.

\section{Ethics approval and consent to participate}

The study was approved by the local ethic review board of the Kushiro Rosai Hospital. Written informed consent was obtained from all study subjects.

\section{Consent for publication}

Written consent for the publication of personal/clinical data was obtained from all study subjects.

\section{Competing interests}

The authors declare that they have no competing interests.

\section{Author details}

1 Department of Gastroenterology, Kushiro Rosai Hospital, Kushiro, Japan.

2 Department of Gastroenterology and Hepatology, Hakodate Municipal Hospital, Hakodate, Japan.

Received: 9 Auqust 2020 Accepted: 12 November 2020 Published online: 11 February 2021

\section{References}

1. Global Burden of Disease Cancer Collaboration, Fitzmaurice C, Dicker D, et al. The global burden of cancer 2013. JAMA Oncol. 2015;1:505-27.

2. Kim YG, Kong SH, Oh SY, Lee KG, Suh YS, Yang JY, et al. Effects of screening on gastric cancer management: comparative analysis of the results in 2006 and in 2011. J Gastric Cancer. 2014;14:129-34.

3. Suh M, Choi KS, Lee YY, Jun JK, et al. Trends in cancer screening rates among Korean men and women: results from the Korean National cancer screening survey, 2004-2012. Cancer Res Treat. 2013;45:86-94.

4. Ono H, Kondo H, Gotoda T, Shirao K, Yamaguchi H, Saito D, et al. Endoscopic mucosal resection for treatment of early gastric cancer. Gut. 2001:48:225-9.

5. Ono H, Yao K, Fujishiro M, Oda I, Nimura S, Yahagi N, et al. Guidelines for endoscopic submucosal dissection and endoscopic mucosal resection for early gastric cancer. Dig Endosc. 2016;28:3-15.

6. Takizawa K, Oda I, Gotoda T, Yokoi C, Matsuda T, Saito Y, et al. Routine coagulation of visible vessels may prevent delayed bleeding after endoscopic submucosal dissection —an analysis of risk factors. Endoscopy. 2008;40:179-83.

7. Oda I, Suzuki H, Nonaka S, Yoshinaga S. Complications of gastric endoscopic submucosal dissection. Dig Endosc. 2014;25:71-8.

8. Higashiyama M, Oka S, Tanaka S, Sanomura Y, Imagawa H, Shishido T, et al. Risk factors for bleeding after endoscopic submucosal dissection of gastric epithelial neoplasm. Dig Endosc. 2011;23:290-5.

9. Okada K, Yamamoto Y, Kasuga A, Omae M, Kubota M, Hirasawa T, et al. Risk factors for bleeding after endoscopic submucosal dissection of gastric epithelial neoplasm. Surg Endosc. 2011;25:98-107.

10. Sugimoto T, Okamoto M, Mitsuno Y, Kondo S, Ogura K, Ohmae T, et al. Endoscopic submucosal dissection is an effective and safe therapy for early gastric neoplasms: a multicenter feasible study. J Clin Gastroenterol. 2012:46:124-9.

11. Goto O, Fujishiro M, Oda I, Kakushima N, Yamamoto Y, Tsuji Y, et al. A multicenter survey of the management after gastric endoscopic submucosal dissection related to postoperative bleeding. Dig Dis Sci. 2012;57:435-9.

12. Azumi M, Takeuchi M, Koseki Y, Kumagai M, Kobayashi Y, Takatsuna M, et al. The search, coagulation, and clipping (SCC) method prevents delayed bleeding after gastric endoscopic submucosal dissection. Gastric Cancer. 2019;22:567-75.

13. Kawata N, Ono H, Takizawa K, Kakushima N, Tanaka M, Igarashi K, et al. Efficacy of polyglycolic acid sheets and fibrin glue for prevention of bleeding after gastric endoscopic submucosal dissection in patients under continued antithrombotic agents. Gastric Cancer. 2018;21:696-702.

14. Kataoka Y, Tsuji Y, Hirasawa K, Takimoto K, Wada T, Mochizuki S, et al. Endoscopic tissue shielding to prevent bleeding after endoscopic submucosal dissection: a prospective multicenter randomized controlled trial. Endoscopy. 2019;51:619-27.

15. Abiko S, Yoshikawa A, Harada K, Kawagishi N, Sano I, Oda H, et al. Combination of search, coagulation, clipping, and polyglycolic acid sheet to prevent delayed bleeding after gastric endoscopic submucosal dissection. Endoscopy. 2020;52:E344-5.

16. Tajiri H, Kitano S. Complication associated with endscopic mucosal resection: definition of bleeding that can be viewed as accidental. Dig Endosc. 2020;16:134-6.

17. Fujimoto K, Fujishiro M, Kato M, Higuchi K, Iwakiri R, Sakamoto C, et al. Guidelines for gastroenterological endoscopy in patients undergoing antithrombotic treatment. Dig Endosc. 2014;26:1-14.

18. Kato M, Uedo N, Hokimoto S, Higuchi K, Iwakiri R, Sakamoto C, et al. Guidelines for gastroenterological endoscopy in patients undergoing antithrombotic treatment: 2017 appendix on anticoagulants including direct oral anticoagulants. Dig Endosc. 2018;30:433-40.

19. Takayama W, Endo A, Koguchi H, Sugimoto M, Murata K, Otomo Y. The impact of blood type $\mathrm{O}$ on mortality of severe trauma patients: a retrospective observational study. Crit Care. 2018;22:100.

20. Kobayashi N, Mori H, Kobara H, Masaki T. Reliable procedure of polyglycolic acid sheet delivery and placement on gastric artificial floor: Application of wafer paper and thread. Dig Liver Dis. 2018;50:724.

21. Takimoto K, Toyonaga T, Matsuyama K. Endoscopic tissue shielding to prevent delayed perforation associated with endoscopic submucosal dissection for duodenal neoplasms. Endoscopy. 2012;44:E414-5. 
22. Japanese Gastric Cancer Association. Japanese Gastric Cancer Treatment Guidelines 2018 (5th Edition). Gastric Cancer 2020 Feb 14.

23. Kanda Y. Investigation of the freely available easy-to-use software "EZR" for medical statistics. Bone Marrow Transplant. 2013;48:452-8.

24. Ono S, Fujishiro M, Yoshida N, Doyama H, Kamoshida T, Hirai S, et al. Thienopyridine derivatives as risk factors for bleeding following high risk endoscopic treatments: Safe Treatment on Antiplatelets (STRAP) study. Endoscopy. 2015;47:632-7.

25. Yoshio T, Nishida T, Kawai N, Yuguchi K, Yamada T, Yabuta T, et al. Gastric ESD under heparin replacement at high-risk patients of thromboembolism is technically feasible but has a high risk of delayed bleeding: Osaka University ESD Study Group. Gastroenterol Res Pract. 2013;10:365830. https://doi.org/10.1155/2013/365830.

26. Cho SJ, Choi IJ, Kim CG, Lee JY, Nam BH, Kwak MH, et al. Aspirin use and bleeding risk after endoscopic submucosal dissection in patients with gastric neoplasms. Endoscopy. 2012:44:114-21.

27. Tounou S, Morita Y, Hosono T, Harada H, Hayasaka K, Katsuyama Y, et al. Endoscopic submucosal dissection for early gastric cancer without interruption of warfarin and aspirin. Endosc Int Open. 2015;3:E307-10.

28. Mukai S, Cho S, Nakamura S, Hatano Y, Kotachi T, Shimizu A, et al. Postprocedural combined treatment using the coagulation plus artery-selective clipping (2C) method for the prevention of delayed bleeding after ESD. Surg Endosc. 2013;27:1292-301.

29. Goto O, Sasaki M, Akimoto T, Ochiai Y, Kiguchi Y, Mitsunaga Y, et al. Endoscopic hand-suturing is feasible, safe, and might contribute in reducing bleeding risk after gastric endoscopic submucosal dissection: a multicenter pilot study (with video). Endoscopy. 2017;49:792-7.

30. Goto O, Oyama T, Ono H, Takahashi A, Fujishiro M, Saito Y, et al. Endoscopic hand-suturing is feasible, safe, and may reduce bleeding risk after gastric endoscopic submucosal dissection: a multicenter pilot study (with video). Gastrointest Endosc. 2020;91:1195-202.

31. Desai J, Granger CB, Weitz JI. Aisenberg J (2013) Novel oral anticoagulants in gastroenterology practice. Gastrointest Endosc. 2013;78:227-39.

32. Hatta W, Tsuji Y, Yoshio T, Kakushima N, Hoteya S, Doyama H, et al. Prediction model of bleeding after endoscopic submucosal dissection for early gastric cancer: BEST-J score. Gut. 2020;4:gutjnl-2019-319926. https://doi. org/10.1136/gutjnl-2019-319926.

\section{Publisher's Note}

Springer Nature remains neutral with regard to jurisdictional claims in published maps and institutional affiliations.
Ready to submit your research? Choose BMC and benefit from:

- fast, convenient online submission

- thorough peer review by experienced researchers in your field

- rapid publication on acceptance

- support for research data, including large and complex data types

- gold Open Access which fosters wider collaboration and increased citations

- maximum visibility for your research: over $100 \mathrm{M}$ website views per year

At BMC, research is always in progress.

Learn more biomedcentral.com/submissions 